Provided for non-commercial research and education use. Not for reproduction, distribution or commercial use.

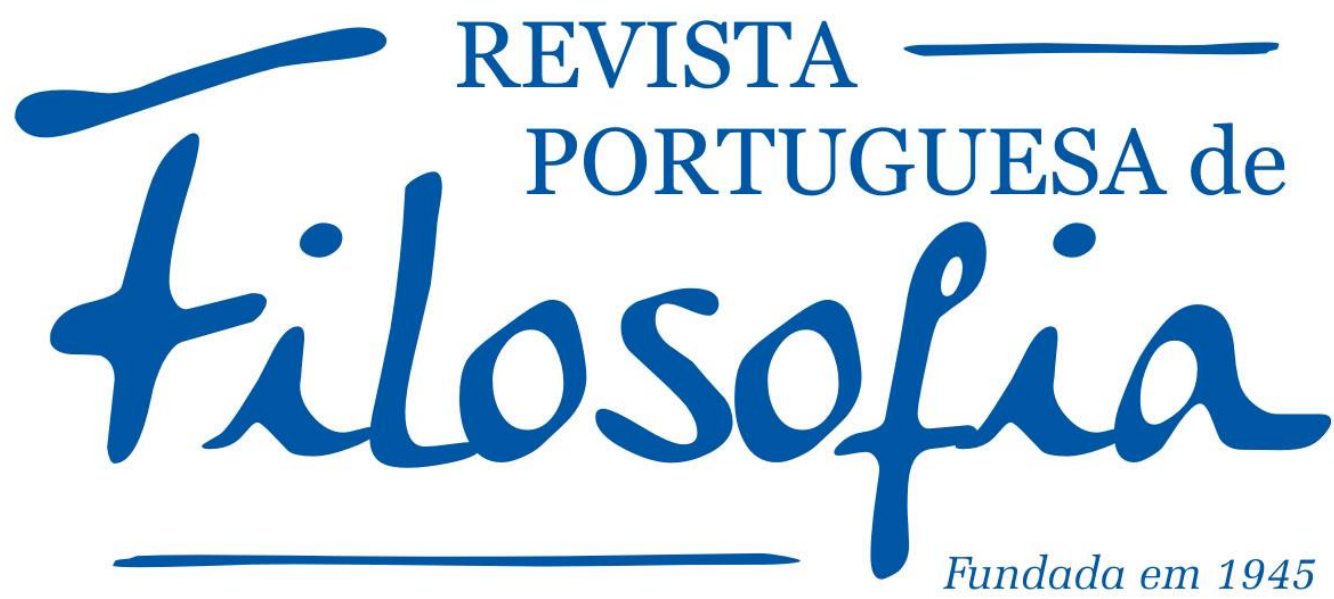

This article appeared in

Direito e Filosofia: Fundamentos e Hermenêutica = Law and Philosophy: Foundations and Hermeneutics / Eds. Álvaro Balsas, SJ; Ricardo Barroso Batista. In: Revista Portuguesa de Filosofia. - Braga. - Volume 70 (2014), Issue 2-3 [ISBN: 978-972-697-223-5; eISBN: 978-972-697-222-8; ISSN: 0870-5283], published by Aletheia - Associação Científica e Cultural.

The attached copy is furnished to the author for internal non-commercial research and education use, including for instruction at the authors institution and sharing with colleagues.

Other uses, including reproduction and distribution, or selling or licensing copies, or posting to personal, institutional or third party websites are prohibited.

Authors requiring further information regarding Revista Portuguesa de Filosofia archiving and manuscript policies are encouraged to visit:

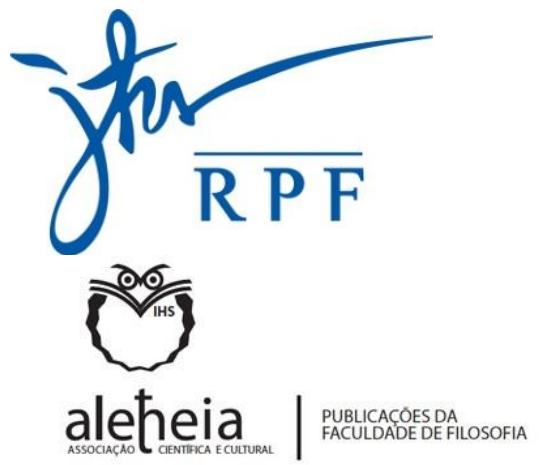

REVISTA PORTUGUESA DE FILOSOFIA

ALETHEIA - Associação Científica e Cultural Faculdade de Filosofia de Braga

Praça da Faculdade, 1

4710-297 BRAGA

Portugal

www.rpf.pt

rpf.aletheia@gmail.com 


\title{
La Filosofía Hermenéutica como Fundamento del Derecho
}

\author{
MIGUEL GRANDE YÁÑEZ*
}

\begin{abstract}
Resumo
Este artigo procura alcançar uma reflexão conceptual na qual, a Filosofia Hermenêutica pode ser instituída como fundamento da Filosofía do Direito e do fenómeno jurídico e, consequentemente, como uma base para futuros desenvolvimentos da actual Filosofia Hermenêutica do Direito, de forma a poder ser alternativa ao Direito Natural e ao Positivismo Legal. Por conseguinte, um conceito chave a ser abordado é o de "ser com", visto que a situação do Mundo promove o surgimento do Direito no seu encontro com outro "ser com". Assim, a relação jurídica ficaria sustentada pela hermenêutica, a partir do conceito central de significado, enquanto profundidade e plenitude do ser jurídico, no qual a sua possibilidade de valorização é estabelecida como sentido de justiça. Assim, a Filosofia Hermenêutica do Direito providenciaria um retorno à ética, à luz do que juridicamente lhe diz respeito, de significados abertos à renovação, permitindo uma maneira de mudar a ideia estática de Filosofia do Direito, porque a justificação não assenta nos conteúdos morais, mas no sentido do ser.
\end{abstract}

Palavras-chave: hermenêutica, mundo, sentido, ser com

\begin{abstract}
This article seeks to achieve a conceptual reflection in which Hermeneutical Philosophy can be established as a foundation for Philosophy of Law and the legal phenomenon, and, thus, as a ground for future developments in the current Hermeneutics Philosophy of Law that can be alternative to Natural Law and Legal Positivism, giving answers to common problems. Consequently, a key concept to be addressed in this article is "be with", since the situation in the world fosters the emergence of Law in its encounter with another "be with". Thus, the legal relationship would be sustained by hermeneutics, from the central concept of meaning as deepness and fullness of juridical being, in which in the possibility of its valuation is established as a sense of justice. So, the Hermeneutics Philosophy of Law would provide a return to ethics, in view of what juridically concerns it, with meanings opened to renovation, allowing a way to change the static idea of Philosophy of Law, because justification is not based on the moral contents, but in the sense of being.
\end{abstract}

Keywords: being with, hermeneutics, meaning, world

*Universidad Pontificia Comillas. mgrande@der.upcomillas.es 


\section{Author's Personal Copy}

Miguel Grande Yáñez

\section{El "ser con" hacia el Derecho}

$\mathrm{E}$ 1 fenómeno jurídico que se reconoce en la intersubjetividad humana parte de un elemento previo esencial cual es el propio ser humano. El ser humano tiene que poder desplegarse en un Mundo vario de posibilidades, bastantes de ellas valorativas. La posibilidad valorativa del ser en el Mundo es una condición previa y necesaria de la juridicidad. En el Mundo hallará el hombre el ámbito en el que le resulta posible el encuentro jurídico con el otro, pero este no sería factible sin la posibilidad de la apertura comprensiva a mundos varios, y por ende a sujetos varios. Es preciso reflexionar más allá de las inercias sociales, varias de ellas jurídicas, sobre la instalación o incluso caída del hombre en el Mundo; esto es también su vivencia y convivencia en el Mundo, aunque no su dominio del Mundo. El Mundo supone en cierto modo naturaleza (aunque no en plenitud comprensiva de orden), pero también artificio, y para nuestro estudio ser-en-relación real en la que puede encontrar plenitud; pero antes ahí está el ser. Heidegger se acerca a esta idea con la referencia del "estado de abierto" respecto del comprender del ser. ${ }^{1}$ Esto ha resultado clave en la mutabilidad de los contenidos predicados, e incluso contrapuestos, por el Derecho Natural.

El ser que es ser en el Mundo precisa ser "ser con" en situación, y con transfondo de Mundo. Esta referencia no puede perderse ni siquiera cuando la depuración de la Hermenéutica jurídica nos traslade al texto, al texto como espíritu. El "ser con", como ser jurídico, es también una apertura de Mundo. Antes que ser "ser con otro" había un ser que podía ser "ser con" para un Mundo, comprensible desde el estado abierto, por ello la Hermenéutica con posibilidad varia y en avance es ineludible. También el ser comprende el Mundo y puede encontrar plenitud en el "ser con" que tiende a lo jurídico en su posibilidad de valoración de justicia. Así el posible jurídico "ser con" se despliega más allá de sí para poder ejercer la comprensión (hermenéutica) del otro, así como también, posiblemente tras la comprensión, la posibilidad del acuerdo del ya "ser con otro". El ser tiende a ser, jurídicamente, ser hacia otros. De este modo surge ontológico-jurídicamente el "ser con otro", que no es ser con las cosas; y por sí solo el ser no es plenitud de ser. ${ }^{2}$ El ser encuentra también en el otro cercanía, similitud, posibilidad da acuerdo, y pacto. p. 101.

1. Cf., Heidegger, M. - El ser y el tiempo. México: Fondo de Cultura Económica, 1998,

2. Surge aquí el problema hermenéutico de la tradición textual donde la temporalidad va más allá del ser ahí con otro en una situación. Con la textualidad se extiende más la universalidad hermenéutica. 
Esta vivencia del ser lo es en la situación del ahí y del aquí. Pero el ser no nace con el otro, sino que encuentra al otro siendo ser, y configura ese encuentro con el otro pues al ser le resulta implícita la creatividad jurídica. El Mundo del ser, el Mundo del ser con otro y el Mundo de la intersubjetividad no son un a priori sino vivencias en el ahí y aquí. En el Mundo es posible la comprensión y el acuerdo, pero no el dominio; esas son posibilidades de libertad, pero hay otras irrealizables porque hermenéuticamente se puede ser consciente de la influencia pero no dominar al Mundo. Esto es ya un problema (y cierta solución) para el operador jurídico. Al principio es cierta también "la caída", un estado de abandono del que la consciencia hermenéutica libera en parte.

El encuentro con el otro es un encuentro experiencial del que surge hermenéuticamente no sólo la comprensión del otro y de esa cercanía el acuerdo (jurídico), sino también acrecentamiento en la comprensión del ser del yo (toda comprensión, incluso más la comprensión del otro es autocomprensión). Es el sujeto del que parte el Derecho y al que retorna, y el conocimiento más posible es del yo antes incluso que esa intersubjetividad tan reclamada; y hasta en cierto punto el otro es un arcano. Ahora bien el encuentro con el otro enriquece mi yo. Este encuentro y autocomprensión se instalan y suceden en el Mundo, como concepto general metafísico en el que no sólo hay hombres, sino también textos.

En cualquier caso no es suficiente en la comprensión hermenéutica jurídica, aunque tenga su relevancia, la noción de situación, tan destacada en Gadamer. Este gran filósofo habla de la comprensión como salto hermenéutico cuando el sujeto ha logrado desplazarse por completo en su juicio a la plena concreción de la situación en la que tiene que actuar el otro. ${ }^{3}$ Sólo es posible aproximarse a esa plenitud de la situación mediante la idea de Mundo; y Mundo como experiencial y hermenéutico. Por ello sí comparto, jurídicamente, con Gadamer, la insuficiencia del saber del espíritu como general Abstracto, la relevancia de lo momentáneo, y para el descifrar esto supone la apelación a una virtud clásica como la phronesis, cuyo desarrollo exige al otro en cuanto comprensión. La relación hermenéutica del hombre como relación jurídica universal afecta a la relación de un hombre con su Mundo. ${ }^{4}$

3. Cf., Gadamer, H. G. - Verdad y método I. Salamanca: Sígueme, 2005, p. 394. Tienen estas posibilidades psicológicas de la Hermenéutica alcance ético y jurídico.

4. Ya Dilthey, como nos explica el profesor Almoguera, entendía el vivir como el mediar el espíritu interno con el espíritu objetivado del mundo externo, precisando esa interacción la constitución de sentido en el espíritu; la vida en definitiva como estructura hermenéutica 
En la relación del "ser con" con los otros no surge (ni se reconoce sustancialmente) una objetividad de lo humano sino un encuentro espacial y temporal en el Mundo en el que se edifica el ser personal de cada uno. El ser personal no es cosificado y tampoco creo que se sustancie como entidad propia intersubjetiva, sino, es cierto, ser relacional comprendido desde el ser individual como ser ahí. El enlace intersubjetivo no se puede metafísicamente aislar o superar a los seres propios enlazados, que son los que hermenéuticamente comprenden, ${ }^{5}$ como desprendidos del Mundo. La Filosofía Hermenéutica como filosofía que supera la representación de sentidos (de lo ajeno) para configurarse en filosofía que constituye sentidos (de lo propio), tiene pues este punto de partida (para el ulterior retorno de la autocomprensión) en el sujeto que se abre y construye jurídicamente con el otro. Pero la comprensión del otro es comprensión del ser, no constitución intersubjetiva sustancial. Y esta constitución comprensiva es una tendencial universalidad de los planteamientos filosóficos hermenéuticos.

\section{Texto y acontecimiento. En la búsqueda del sentido jurídico}

El ser no se cosifica, lejano queda de ello, por el sentido, debido al sentido (de un ser en estado abierto), el cual jurídicamente viene perfilado desde lo justo valorativo. En la comprensión e interpretación del Mundo y del Mundo jurídico preside el sentido. El sentido es entraña del ser. El sentido jurídico frente a otras estructuras férreas objetivas y concretas viene posibilitado en su intensidad ontológica y en su variación práctica por ese carácter de estado abierto. Así la ley natural se ve desplazada en la libertad por el sentido de cada ser que puede ser sentido de justicia al ser el ser "ser con" otro. El sentido es también anhelo por lo que puede para el ser tener sentido, o puede para el ser carecer de sentido (en sus comprensiones de un Mundo como "ser con"), vivir en un sinsentido; y por ello jurídicamente decidir sinsentido jurídico. El sentido colma en plenitud a los seres, que también pueden comprender una vida o una historia sinsentido, como propio o fundamentalmente cuando se predica de otros seres.

fundamental ( $c f$., Almoguera, Joaquín - "Filosofía hermenéutica y Filosofía del Derecho". Icade, 82 (2011), p. 233).

5. Por su parte Kaufmann con el énfasis más en la relación del ser que en el "ser con", habla para la construcción jurídica de la necesidad de cambio de la ontología sustancial a la ontología relacional (cf., KaUfmann, Arthur-Hermenéutica y Derecho. Granada: Comares, 2006, p. 121). 
La fuerza hermenéutica del sentido implica en primer lugar una superación de lo meramente lingüístico y de la filosofía lógico analítica. Por ello también resulta insuficiente el positivismo jurídico. Según Paul Ricœur, con motivo de su análisis de la cercanía y deuda intelectual de la fenomenología y la hermenéutica, ambas comparten el carácter derivado de los significados de orden lingüístico. Incluso sostiene Ricœur, no siendo en ello el único autor, que en Gadamer se constata un carácter secundario de la problemática del lenguaje. ${ }^{6}$ Tal vez la expresión carácter secundario resulte un tanto desmesurada, pues en Gadamer la conformación lingüística del hombre del Mundo es clave (sólo el hombre que conoce y domina el lenguaje en una lengua conoce el Mundo). Otra cuestión es que en ocasiones Gadamer apunte a realidades filosóficas más allá del lenguaje, con lo que abre una vía de posibilidad hermenéutico-jurídica que vuelve a desbordar el positivismo.

Lo que Ricœur ${ }^{7}$ hace incidencia frente a Gadamer, precisamente en la búsqueda de la analogía entre fenomenología y hermenéutica, y con gran calado jurídico, es en el alcance definitivo de lo experiencial, a lo cual se remite también el orden lingüístico. Esto es un presupuesto fenomenológico de la hermenéutica el cual también faculta para una aproximación a lo textual en la que esté casi más presente que el lenguaje el sentido de la experiencia. La hermenéutica gadameriana centrada, aunque no anclada, en lo textual, se prolonga y completa con ese salto experiencial a la acción y al acontecimiento como sentido. En proyección jurídica esto también invita a un movimiento determinante hermenéutico como salida al positivismo jurídico.

Esta mirada desde el texto al acontecimiento hace más necesaria y persuasiva nuevamente la noción de Mundo, como Mundo del intérprete. Por ello la interpretación es una explicitación lingüística del sentido de ser en el Mundo que el texto ${ }^{8}$ ha desplegado al intérprete. Aquí resulta más necesaria en el sentido jurídico la condición valorativa del intérprete conformada o guiada por su estructura del Mundo. El intérprete

6. Cf., Ricenur, P. - Del texto a la acción. Ensayos de hermenéutica II. México: Fondo de Cultura Económica, 2011, p. 57. Sobre la relación iusfilosófica entre analítica y hermenéutica puede consultarse: ZACCARIA, G. - "Entre hermenéutica y analítica: del contraste a la colaboración”. Anuario de Filosofía del Derecho, X (1993), pp. 291-323.

7. $C f$., Riceeur, P. - Op. cit., p. 58. Habla incluso Ricœur de "preparar el desplazamiento del problema del texto hacia el mundo que abre" (p. 96).

8. Si bien Gadamer, como se ha comentado, no llega como otros a la fuerza hermenéutica del acontecimiento experiencial, sí se refiere a la escritura como la verdadera espiritualidad del lenguaje (que en el sigue siendo fundamental); la conciencia comprensiva tiene en la tradición escrita su plena soberanía ( $c f$. , Verdad y método I, ed. cit., p. 470).

Fascs. 20 -3 7 tor 2014 
jurídico, aunque creativo, no lo es sólo de un texto que rememora o configura sino de una decisión en su contexto de Mundo, la cual desde el sentido y mediante el lenguaje explicita. El lenguaje y su formalización estructural como discurso son medios o incluso métodos en los que el sentido se espiritualiza con mayor rigor y sobre todo profundidad, pues la palabra pronunciada en el tiempo debilita la posibilidad interpretativa y con ella la plenitud del sentido. Del mismo modo el acontecimiento experiencial y también lingüístico encuentra en el discurso del texto más posibilidad de reflexión filosófica y por tanto de ulterior decisión valorativa (jurídica).

Si ya remarcar el alcance del sentido es una cuestión sutil y de asombro, reflexionar sobre la primera comprensión del sentido de un texto o de una experiencia es un tema no exento de enigma. El sentido, el sentido del ser, sobre todo como valorativo, brota, en ocasiones impetuoso, y determina la reflexión y la vida y también la convivencia. La confianza filosófica en el sentido desplaza la razón objetiva. También es cierto que el sentido, como el gusto, puede ser objeto de experiencia, de cultivo. El sentido variable, tan variable con el decurso temporal, se determina como posible por ese estado abierto del ser. No poco se ha hablado también del carácter altamente hermenéutico de la anticipación del sentido, que guía, en el comienzo en tinieblas, la interpretación y que orienta y determina la plenitud de sentido y su repercusión filosófica. Este sentido que se anticipa ingenioso, aunque ya fruto de la experiencia intelectual (profesional) resulta determinante en las decisiones judiciales e incluso en el proceso y metodología de argumentación justificativa de las mismas. Es también esta anticipación de sentido jurídico una anticipación de sentido de justicia en el ser.

Vitalmente sentidos ulteriores se apoyan en el cultivo de la phronesis. La Hermenéutica no es extraña respecto de la virtud moral de la prudencia. También el sentido de justicia en su brotar y en el alcance de su plenitud es objeto de reflexión y experiencia prudencial. La clave está también en trasladar en esta línea, la Filosofía y la Filosofía del Derecho a un momento aplicativo experiencial que se formaliza como argumentación textual, conjugando lo general y lo particular, pero enfocando en tal conjugación el sujeto en situación y circunstancia. Esta operatividad prudencial, reflexiva, limita, no obstante, el subjetivismo arbitrario, del que hablaremos, distanciándonos, algo más adelante.

Nos ubicamos, pues, en la Filosofía del Derecho Hermenéutica en una filosofía práctica, no apriorística y sí experiencial, y tan pronto abierta como prudente. Con la proyección del texto a la realidad ${ }^{9}$ como

9. El profesor Joaquín Almoguera también se ha referido a la Filosofía Hermenéutica como una filosofía no limitada a los textos, sino abierta a la comprensión de la realidad 
acontecimiento vital, también intersubjetivo (aunque no sustancial), determinamos con la Hermenéutica una labor no receptiva que simplemente represente sentidos, sino configuradora, conformadora de sentidos como experiencias de plenitud, apoyadas espiritualmente en textos con alcance valorativo. ${ }^{10}$ Esta Filosofía jurídica hermenéutica no es pues una cuestión técnica o instrumental, esto es, metodológica, sino fundadora y fundamentadora del Derecho. Para ello precisa del sentido jurídico (que se lanza en proyección de sentido de justicia) del sujeto que comprende en el Mundo la posibilidad de intersubjetividad. Como en la Filosofía fundamental, la Hermenéutica en el Derecho ha seguido un camino, que descubrimos, construimos y transitamos, un camino expansivo-reflexivo y en proyección universal.

La Filosofía del Derecho Hermenéutica no es una filosofía ideal, sino una filosofía práctica ${ }^{11}$ que se apoya en un concepto vital valorativo como es el sentido en cuanto sentido de justicia. Es la Filosofía del Derecho

general y extendida a disciplinas como la ontología, la ética o la estética; así la hermenéutica filosófica se convierte en Filosofía Hermenéutica en la que la realidad surge como objeto interpretativo; los objetos de la realidad se acogen en la conciencia y de este modo tan pronto se difiere de las ciencias de la naturaleza como el sentido se convierte en un problema ineludible ( $c f$. , Almoguera, Joaquín - "Filosofía hermenéutica y Filosofía del Derecho", art. cit, p. 233).

10. Cabe recordar ahora a Karl Larenz cuando insistentemente en su Metodología de la Ciencia de Derecho, habla del Derecho (o la Filosofía del Derecho) como pensamiento orientado a valores; si bien en Larenz la hermenéutica sería más metodología que filosofía.

11. En esta línea de Filosofía práctica, y también en superación hermenéutica de una dimensión estrictamente textual, Zaccaria y Viola señalan que la "cosa" de la que habla un texto (jurídico) vive como comprensión e interpretación en la práctica (cf., Derecho e interpretación. Elementos de teoría hermenéutica del Derecho. Madrid: Dykinson, 2007, p. 424). Suele resultarme significativo cómo estos autores conceden más relevancia a la noción de comprensión que a la de interpretación. En Gadamer, por ejemplo, encontraremos comprensión interpretativa en cuanto primacía hermenéutica de la interpretación (o resultado interpretativo). En intensificación de esta línea hermenéutica, que frente a Gadamer va rebajando el papel filosófico del texto, Pedro Serna se refiere al mismo como el "signo" de la interpretación, pero no constituye el texto el objeto de la interpretación ni el horizonte de la comprensión ( $c f$., SERnA, P. - "Hermenéutica y relativismo. Una aproximación desde el pensamiento de Arthur Kaufmann". In: De la argumentación jurídica a la Hermenéutica. Granada; Comares, 2005, p. 294). No obstante si bien hemos seguido con Ricœur el salto al acontecimiento, no hemos de dejar de insistir en el adentro espiritual hermenéutico que el texto posibilita, en saberes filológicos, teológicos y jurídicos, aunque en estos la necesidad y justificación de tender desde el texto a una filosofía de la praxis es más evidente. Así en su recorrido histórico hermenéutico Rodríguez Puerto nos informa como según Osuna en el Derecho, frente a la amplia multiplicidad de interpretaciones propias del ámbito literario, es preciso establecer límites como por ejemplo los determinados por la Dogmática ( $c f$., Rodríguez Puerto, M. J. - Interpretación, Derecho e Ideología. La aportación de la Hermenéutica jurídica, Granada: Comares, 2011, p. 108). 
Hermenéutica una filosofía no sustancial ni formal sino experiencial, y por ello en ella, pese a la tendencia ontológica a la universalidad, las categorías sustanciales no tienen primado, pues la misma surge de la situación en circunstancia de perspectiva o instalación vital valorativa. La Filosofía del Derecho Hermenéutica precisa de un ser que comprende en estado abierto, en el Mundo que en tantas situaciones le resulta extraño o sorpresivo, y en esta comprensión interpretativa de la situación mundana como ser humano se autonomiza otorgándose un sentido de esa situación. Lo textual le ayuda en la profundidad y plenitud de tal sentido. Pero antes está lo extraño al ser, que si no se desvela puede originar el sinsentido; en la Filosofía del Derecho Hermenéutica la ausencia de la comprensión de lo justo. El ser también es capaz de detectar sentidos ajenos o sentidos en comunidad, y esto ayuda en la comprensión de la dimensión jurídica, en la que, admitiendo el encuentro intersubjetivo, hemos preferido no dotarle de la sustancialidad de la metafísica clásica, sino de experiencia que principia el sentido del ser, llamado a ser "ser con".

La subsunción lógica o la metodología estricta o mecánica desligadas de esa realidad experiencial hermenéutica se desprenden, pues, de esta Filosofía del Derecho, frente lo sucedido en corrientes iuspositivistas. Es, pues, decisivo la experiencia convivencial de la vida del sujeto valorativo que se encuentra con el otro o con otros seres, en una atmósfera de Mundo y tradición. El sentido de esta experiencia vuelve a ser la hendidura hermenéutica de lo humano. El sentido como sentido jurídico de justicia puede refinarse en la trayectoria vital profesional de profesionales del Derecho, sobre todo jueces. Alejados del formalismo jurídico y buscando decisiones jurídicas en situaciones resulta preciso para remontar arbitrariedades, decisiones incomprensibles o ininterpretables por su sinsentido, ahondar aún con la dificultad (filosófica) de la comprensión, ahondar en el sentimiento jurídico. Rodríguez Puerto ${ }^{12}$ aproxima este sentimiento jurídico a la antigua phronesis en cuanto virtud que capta las exigencias éticas de la situación real; el sentimiento jurídico es también para él realidad comunitaria de base sociológica. Dada la relevancia valorativa del ser la phronesis no es suficiente pues también precisa actuar con la epieikeia. En ambos casos remontamos jurídico-judicialmente la centralidad jurídica normativa, no en cuanto prescindir de las normas sino en relativizar su fortaleza o sacralización jurídica, pues sin la situación (caso)

12. Cf., Rodríguez Puerto-Op. cit., p. 19, p. 113. Resulta frecuente el recurso de los filósofos hermenéuticos a retomar conceptos de la filosofía griega, sobre todo la aristotélica, posiblemente por su captación de la realidad práctica. Heidegger significó el interés de los griegos en la filosofía contemporánea por la contención de la subjetividad.

Fascs. 20 -3 7 tor 2014 
en interpretación y ulterior decisión argumentativa la norma sólo flota como lenguaje.

Surge aquí el problema de la anticipación de la decisión a partir del comienzo y proyección de la captación de sentido, en el que no sólo la norma sino también la propia argumentación jurisprudencial pueden convertirse en pretexto; por ello nuevamente la necesidad de la confianza en el sentido y en el enfrentamiento al sinsentido. El Derecho es pues experiencia (experiencia en reflexión [textual]). Por eso con un nuevo alcance valorativo frente por ejemplo a la tradición iusnaturalista emerge la noción gadameriana de acierto. Así la argumentación por si sola o como centralidad es insuficiente para una Filosofía del Derecho contemporánea, pues es precisa la ontología narrada del ser que tiende a ser ser jurídico. Y en ello la filosofía de Gadamer como filosofía fundamental inspiradora de varias incursiones iusfilosóficas hermenéuticas ha resultado valiosa, pero aun así es posible complementarla o completarla con esas otras sendas hermenéuticas que vamos transitando, y que ayudan como comprensión de la realidad experiencial a desterrar infundados reproches de arbitrariedad. En esta problemática seguimos ahondando en el apartado siguiente.

\section{Insuficiencia de la objetividad sustancial y del subjetivismo en el Derecho}

El sujeto concebido ontológicamente como ser-ahí determina la subjetividad del Mundo, aun en el encuentro con el otro; pero en cuanto la temporalidad trasciende al sujeto, a todo sujeto, también se concibe a partir de ella una marcada objetividad filosófica. Esta comprensión de la objetividad del ser por el tiempo implica que la filosofía práctica precise ubicarse en momento y situación, y prescindir así de la objetividad sustancial universal atemporal tan propia del Derecho Natural. La hermenéutica va a ensalzar también al momento, como circunstancial, de la interpretación, en el que se adquiere un específico sentido, y no otro.

En cuanto la interpretación se basa inicialmente, y también con relevancia, en un texto que está-ahí dado, y como esa interpretación es posible para todos los sujetos que conocen el lenguaje del texto; así en cierto modo la Hermenéutica y el Derecho como situación se convierten en reflexiones de planteamiento objetivo. Este acceso al texto por el conocimiento común del lenguaje es un elemento para contener la subjetividad, pues los hombres participan en la comprensión del Mundo de un mismo lenguaje, si bien cuestión diversa que individualiza es la adquisición de sentido del Mundo o de sentido del texto por un sujeto. Por esto la objetividad única

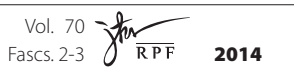




\section{Author's Personal Copy}

Miguel Grande Yáñez

y absolutamente sin determinaciones subjetivas de sentido no es posible en la Hermenéutica, como tampoco lo es, -dados los condicionantes de lenguaje, facultades comprensivas, experiencia compartida, o acceso a la tradición-, tampoco lo es la arbitrariedad. Por eso el sujeto puede sostener, argumentar o convencer que una interpretación es absurda o irracional, un sinsentido en cualquier caso. Partimos en nuestros planteamientos del ser del sujeto, pero esta subjetividad en el encuentro con el otro experiencial queda contenida. Lo que resulta preciso también en la comprensión es ese encuentro, pues la filosofía se libera del idealismo de la autoconciencia.

Por sí solos los conceptos de sujeto y objeto son inadecuados. El sujeto interpreta un cuasi objeto (pues su origen está en el sujeto) con condicionantes trascendentes. El acceso a la interpretación del otro sujeto en tendencia universal también supone objetivación. Estas moderaciones y replanteamientos de las categorías de objeto y sujeto determinan iusfilosóficamente una crítica a la subjetividad política creadora del Derecho que legitimaba el iuspositivismo, o a la sustancialidad objetiva del contenido del Derecho Natural.

La necesidad de interpretación espiritual en el Derecho aleja nuestra disciplina de una objetividad propia de las ciencias naturales donde la conciencia del sujeto queda anulada por la relación causa-efecto física. Ahora bien, como señala Kaufmann, más en variación al iusnaturalismo, el abandono hermenéutico de la concepción objetivista de la comprensión no significa un giro hacia el subjetivismo. ${ }^{13}$ Desde Gadamer se ha entendido el concepto de tradición común y compartida como una noción hermenéutica superadora del subjetivismo individual. En la participación vital valorativa de una tradición se ha tratado de justificar la anticipación del sentido que tan decisiva resulta en la aplicación jurídica y en su comprensión iusfilosófica.

También en esta dicotomía se ha buscando una solución con la idea de intersubjetividad, la cual tiene igualmente su recorrido iusnaturalista (natura rei). La intersubjetividad es de difícil ubicación fuera de la sustancialidad o del consenso. No sólo para llegar a la intersubjetividad sino en la propia dimensión hermenéutica central de la interpretación quien domina es un sujeto, si bien un sujeto que encuentra sentido en el "ser con".

En la Hermenéutica la interpretación textual toma un rumbo de objetividad determinado por la lejanía de la fuerza del creador, y la preponderancia del intérprete que opera con "la cosa" texto en una circunstancia que por la tradición no es sólo la suya, sino también la de su contexto.

13. Cf. Kaufmann, Arthur-Hermenéutica y Derecho, ed. cit., p. 118.

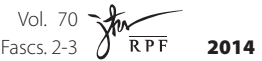


En esta nueva experiencia hermenéutica la obra de Gadamer ha resultado de alcance. Así Gadamer debatía con Betti, ${ }^{14}$ para quién el texto era siempre, aun con su origen, instancia objetiva en sí misma no moldeable por el intérprete hic et nunc.

En esta concepción hermenéutica, en cierto modo nueva, es lógico que el protagonismo jurídico se desplace del legislador al juzgador. También en cierto modo posible en términos de la hermenéutica, el propio texto tiene un diseño y peso metafísico pues su enunciado es ontológicamente en sí mismo. Por eso también el intérprete puede ser insensato o irracional. En este momento el Derecho se centra en su aplicación como experiencia de vida valorativa profesional, y se distancia del nacimiento Abstracto o político.

La Hermenéutica supera pues la subjetividad aunque su planteamiento parte del sujeto. La comprensión, que implica reflexión, en cualquier caso no es un deseo, pero tampoco es una tendencia teleológica, dada su creatividad. La mera subjetividad queda transcendida por un sujeto que se ha conformado en el tiempo del Mundo como "ser con". En el auge del momento aplicativo la hermenéutica gana en pluralidad y se desencadena de la sustancia que también podía proponer el único principio o respuesta correcta. Pero como tantas veces se ha escrito esto no implica caer en el relativismo, pues la Hermenéutica también debe iluminar la interpretación incorrecta, la interpretación y la aplicación jurídica sinsentido.

La historicidad es decisiva en este espacio hermenéutico del "ser con" en estado abierto que se abre paso frente a la sustancia objetiva y la subjetividad infundada. Así es valioso siempre la distancia crítica y la posibilidad de variación, hasta del mismo sujeto, pero siempre desde la perspectiva reflexiva de un ser que se proyecta fuera de sí mismo a otras realidades. Es cierto también que muchos autores han tratado de solucionar problemáticas de esta tipo con la intersubjetividad (ya sustancial, ya consensual ${ }^{15}$ ).

14. Sobre la relevancia de la instancia objetiva en la interpretación según Betti puede consultarse la obra de Rodríguez Puerto, M. J. - Interpretación, Derecho e Ideología. La aportación de la Hermenéutica jurídica, ed. cit., p. 76. Este mismo autor se refiere a la evolución del pensamiento de Kaufmann desde un objetivismo ontológico aunque no sustancialista a una visión hermenéutica superadora de la diferencia entre sujeto y objeto, llegando a hablar de una "ontología relacional"; para Kaufmann es inadmisible negar alguna objetividad (siempre no sustancialista) fuera de las formas procedimentales (cf., ibídem, pp. 78-80).

15. Pedro Serna destaca como Kaufmann se distanció del fundamento del consenso en relación con el problema de la verdad, oponiendo a ello hermenéuticamente la tesis de los conocimientos convergentes objetivos en la circunstancia de la cercanía o coincidencia de muchos sujetos independientes entre sí en relación con el mismo asunto ( $c f$., Serna, Pedro - "Hermenéutica y relativismo. Una aproximación desde el pensamiento de Arthur Kaufmann”. In: De la argumentación jurídica a la Hermenéutica, ed. cit., p. 315). 


\section{Author's Personal Copy}

Miguel Grande Yáñez

Nosotros preferimos hablar del "ser con" que encuentra y descubre "otro ser con" en el espacio de un Mundo que le trasciende. El sujeto prima, y la Hermenéutica vuelve a él como autocomprensión, pero la Hermenéutica trasciende la mera subjetividad. ${ }^{16}$

En la Hermenéutica jurídica iusfilosófica es relevante la observación de la tarea judicial en la que las decisiones superan el subjetivismo arbitrario al racionalizar desde patrones hermenéuticos sentimientos valorativos. La Hermenéutica aleja la irracionalidad de la decisión judicial. Así el papel del ordenamiento jurídico, más que el de constituir la certeza o seguridad de la decisión es el de ayudar a evitar la infundada subjetividad. Pero ese ordenamiento jurídico es matizado por las valoraciones axiológicas del profesional que argumenta y decide siempre en situación de Mundo. La ley, pese a toda su objetividad Abstracta, carece de realidad de praxis sin el sujeto, y este sujeto decide y persuade en una circunstancia de Mundo que trasciende su relativa subjetividad.

No olvidemos también en estas condiciones de la interpretación como hasta la misma determinante anticipación de sentido viene altamente mediatizada aun en su surgimiento en el sujeto, por instancias más objetivas como la comunidad y la tradición. Por eso ni siquiera la anticipación de sentido (que es respecto de un objeto texto) es absolutamente subjetiva. La noción de tradición como hermenéutica no se cosifica tampoco, pues sus actualizaciones por los sujetos mediatizados la reviven y actualizan. Metafísica sustancial y relativismo se alejan de la Hermenéutica. En este camino que entre dos aguas emerge es comprensible el valor de la phronesis y de la epieikeia. La vida práctica del Derecho es elección en el Mundo, y esto no es autoconciencia y tampoco dada su versatilidad verdad universal. Surgen y se potencian así nociones como elección, conveniencia o corrección.

Jurídicamente se trata de descubrir la posibilidad de criterio en nuestras decisiones, criterio que puede ser explicado, persuadido, compartido; pero este criterio también puede ser variable y por tanto no le es propio el anclaje de la metafísica inmutable. Por eso lo propio de la Hermenéutica no son los contenidos ni tampoco cualquier decisionismo surgido de la voluntad irreflexiva. Y nuevamente aquí ofrece incursión el

16. Con buen criterio Pedro Serna avisa que la comprensión del sujeto no es de naturaleza meramente individual, pues se encuentra instalada en el seno de la tradición y mediada por el lenguaje, siendo así la comprensión transubjetiva ( $c f$., SERnA, Pedro - Op. cit., p. 303). Tradición como hermenéutica y lenguaje como condición de comprensión objetivan el mero subjetivismo, pero sin objetivizar idealmente. Parece como si la hermenéutica fuera una nueva categoría epistemológica e incluso moral diversa al subjetivismo y al objetivismo.

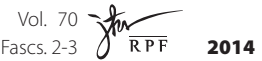


sentido que en la situación clarifica lo sensato de lo insensato. Autores varios no han cesado en el empeño de superar la subjetividad u objetividad en nociones como intersubjetividad, ontología de la circunstancia u objetividad relativa. Así también no parece lejano el repensamiento hermenéutico de un Derecho Natural histórico de contenido variable que alumbre la decisión. Ontológica (jurídicamente) nos referimos al sujeto como valorativo "ser con" en el Mundo.

Para evadirse del subjetivismo y también de la sustancialidad es básico el texto previo, que recordemos no restringía la vivencia y que también a partir de él la Filosofía Hermenéutica se autentificaba en el acontecimiento; si bien el texto espiritualiza con tal alcance que se convierte en algo que es previo y con lo que se enfrenta una conciencia que en su extrañeza precisa la reflexión. Pero es que además el texto tiene que ser interpretado por un sujeto, aunque éste interpreta en y para el Mundo.

En los estudios recientes iusfilosóficos hermenéuticos Rodriguez Puerto $^{17}$ destaca la tesis de Pedro Serna en relación con esta nueva tierra filosófica, que necesitaba en su asentamiento completarse con otras aportaciones iusfilosóficas. Por mi parte, y ante el convencimiento del poder intelectual del discurso hermenéutico, creo que ésta filosofía no precisa de otras herencias, de las cuales además se aleja, sino que una clave puede venir dada por la reflexión sin sesgo ideológico de una ética de la hermenéutica iusfilosófica.

La ética de una hermenéutica jurídica no puede entenderse fundamentalmente como una ética jurídica social, dado el alcance filosófico concedido al concepto de Mundo, y dada también la significada fortaleza del "ser con" a partir de su comprensión del "ser con otro". La vida que no deja de ser coexistencia es interpretada con ojos jurídicos a partir del encuentro ético del "ser con" con el otro ser, y a partir de un sentido de justicia. Este es también en ocasiones un sinsentido de justicia, pues la ética de la Hermenéutica jurídica se evidencia en el conflicto circunstancial.

De este modo en la Hermenéutica jurídica la más alta cota se descubre en la resolución jurisprudencial para el conflicto experiencial entre partes, y no en la legislación general, más Abstracta, menos experiencial, y posiblemente más próxima al fenómeno político que al jurídico el cual resulta más práctico circunstancial. El sentido de justicia aparece en la decisión política (que también tiene alcance valorativo para el "ser con"); pero posiblemente alcance plenitud en la vivencia del "ser con" con otro, y sobre

17. Cf., Rodríguez Puerto - Op. cit., p. 102.

Fascs. 20 -3 7 tor 2014 
todo en la necesidad de reacción (algo tan propio del Derecho) con motivo de la decisión jurisprudencial al conflicto entre varios "ser con". En esta decisión la dialéctica entre la ley (como cosa dada) y el sujeto intérprete se objetiva o desubjetiviza más por la llamada equitativa del conflicto. La esfera jurídica más reconocible, aunque el encuentro del "ser con" con otro como Derecho esté presente en la convivencia, se produzca con motivo del texto de la resolución judicial ${ }^{18}$ que formaliza lingüística y éticamente la decisión hermenéutica del profesional jurídico. El Derecho, pues, como una vivencia del sentido de justicia que el "ser con" condiciona, vivencia de sentido de justicia cuya más depurada, incluso espiritual expresión, se halla en la resolución judicial que con la phronesis y epieiqueia resuelve un conflicto, con persuasión argumentativa, entre partes (un conflicto entre "seres con").

El carácter fáctico de la Filosofía hermenéutica jurídica en la que lo textual se presenta como insuficiente se pone de manifiesto en el origen del conflicto de los "seres con" como acontecimiento. La acción y la realidad no pueden sino asociarse y revivirse en el texto hermenéutico jurídico. También la posibilidad de imaginación espiritual en las exigencias éticas del Derecho es mucho menor que en otras disciplinas humanísticas, como la literaria o incluso la teológica. El texto jurídico, aunque espiritualiza, surge de la acción entre "seres con" y a ellos retorna. También ha mediado en la facticidad la exigencia hermenéutica de la reflexión (especialmente en relación al conflicto), cuya realización comprensiva para el Mundo fructifica en el texto jurídico. En esta reflexión textual el mero acontecer queda sobrepasado. Esta ética de la Filosofía del Derecho Hermenéutica precisa en la mediación equitativa del sujeto intérprete de los valores que guían la decisión como sentido hermenéutico, posiblemente anticipatorio, en un espacio, situación y tiempo de Mundo que trasciende (objetivamente) a ese mismo sujeto decisorio.

18. La retórica clásica también está presente en la Filosofía del Derecho Hermenéutica, pues el lenguaje no es mera sofística sino expresión medida y rigurosa de la plenitud de sentido del ser jurídico. 